\title{
CALORIE RESTRICTION MODIFIES UBIQUINONE AND COQ TRANSCRIPTS LEVELS IN MOUSE TISSUES
}

\author{
Cristina Parrado ${ }^{1,2}$, Guillermo López-Lluch², Elisabet Rodríguez-Bies ${ }^{2}$, Sara Santa-Cruz², \\ Plácido Navas ${ }^{2}$, Jon J. Ramsey ${ }^{3}$, and José M. Villalba ${ }^{1,{ }^{*}}$ \\ ${ }^{1}$ Departamento de Biología Celular, Fisiología e Inmunología, Facultad de Ciencias, Universidad \\ de Córdoba, E-14014, Córdoba, Spain \\ ${ }^{2}$ Centro Andaluz de Biología del Desarrollo,Universidad Pablo de Olavide-CSIC, CIBERER, \\ Instituto de Salud Carlos III, E-41013, Sevilla, Spain \\ ${ }^{3}$ VM Molecular Biosciences, University of California, Davis, CA 95616 USA
}

\begin{abstract}
We studied ubiquinone (Q), Q homologue ratio and steady-state levels of $m C O Q$ transcripts in tissues from mice fed ad libitum or under calorie restriction. Maximum ubiquinone levels on a protein basis were found in kidney and heart, followed by liver, brain and skeletal muscle. Liver and skeletal muscle showed the highest $\mathrm{Q}_{9} / \mathrm{Q}_{10}$ ratios with significant inter-individual variability. Heart, kidney, and particularly brain exhibited lower $\mathrm{Q}_{9} / \mathrm{Q}_{10}$ ratios and inter-individual variability. In skeletal muscle and heart, the most abundant $m C O Q$ transcript was $m C O Q 7$, followed by $m C O Q 8, m C O Q 2, m P D S S 2, m P D S S 1$ and $m C O Q 3$. In non muscular tissues (liver, kidney and brain) the most abundant $m C O Q$ transcript was $m C O Q 2$, followed by $m C O Q 7, m C O Q 8, m P D S S 1$, $m P D S S 2$, and $m C O Q 3$. Calorie restriction increased both ubiquinone homologues and $m P D S S 2$ mRNA in skeletal muscle, but $m C O Q 7$ was decreased. In contrast, $\mathrm{Q}_{9}$ and most $m C O Q$ transcripts were decreased in heart. Calorie restriction also modified $\mathrm{Q}_{9} / \mathrm{Q}_{10}$ ratio, which was increased in kidney and decreased in heart without alterations of $m P D S S 1$ or $m P D S S 2$ transcripts. We demonstrate for the first time that unique patterns of $m C O Q$ transcripts exist in muscular and nonmuscular tissues, and that $\mathrm{Q}$ and $C O Q$ genes are targets of calorie restriction in a tissue-specific way.
\end{abstract}

\section{Keywords}

Calorie restriction; $C O Q$ transcripts; Ubiquinone; Ubiquinone biosynthesis

\section{Introduction}

Ubiquinone (coenzyme $\mathrm{Q}, \mathrm{Q}$ ) is a prenylated benzoquinone which plays a fundamental role shuttling electrons from Complex I and Complex II to Complex III in the mitochondrial electron transport chain [1,2]. Other functions of Q include the mitochondrial oxidation of

(C) 2010 Elsevier Inc. All rights reserved.

* Correspondence to: Departamento de Biología Celular, Fisiología e Inmunología Facultad de Ciencias, Universidad de Córdoba; Campus Rabanales, Edificio Severo Ochoa, $3^{\mathrm{a}}$ planta; 14014 Córdoba, Spain; Phone: +34-957-218595; Fax: +34-957-218634; jmvillalba@uco.es.

Publisher's Disclaimer: This is a PDF file of an unedited manuscript that has been accepted for publication. As a service to our customers we are providing this early version of the manuscript. The manuscript will undergo copyediting, typesetting, and review of the resulting proof before it is published in its final citable form. Please note that during the production process errors may be discovered which could affect the content, and all legal disclaimers that apply to the journal pertain. 
dihydroorotate in the pyrimidine biosynthesis pathway [3,4], protection against oxidative stress as the only lipid-soluble antioxidant which is synthesized in all organisms [1,2], and electron transport as a carrier in the transplasma membrane redox system [5]. A number of proposed functions for $\mathrm{Q}$ are less defined from a molecular point of view. These include modulating the sensitivity of mitochondrial uncoupling proteins (UCPs) to purine nucleotides by $\mathrm{Q}$ redox state, regulating the mitochondrial permeability transition pore activity [7], and inhibiting plasma membrane neutral sphingomyelinase [8]. Q is positioned in a privileged position because it links basic aspects of cell physiology such as energy metabolism, antioxidant protection, and the regulation of cell growth and death.

Although dietary $Q$ is incorporated to some extent in particular tissues, under normal conditions its de novo synthesis accounts for the majority of $\mathrm{Q}$ present in peripheral tissues $[1,2,9,10]$. The precursor of the benzoquinone ring is 4-hydroxybenzoate, whereas the synthesis of the isoprenoid side chain starts from acetyl-coenzyme A to yield farnesyl pyrophosphate (FPP) through the mevalonate pathway $[1,2,11]$. The trans-prenyltransferase activity, a tetramer composed of PDSS1 and PDSS2 gene products [12,13], catalyzes the condensation of FPP with several units of isopentenyl pyrophosphate (IPP), all in trans configuration, to form a long polyisoprenoid chain whose length, 9 or 10 isoprene units in mammals, determines the actual isoform which is synthesized ( $\mathrm{Q}_{9}$ or $\mathrm{Q}_{10}$, respectively) $[1,2]$. Then, 4-hydroxybenzoate and polyprenyl pyrophosphate are condensed by polyprenyl 4-hydroxybenzoate transferase, encoded by $C O Q 2$ [14]. After condensation, at least six enzymes (encoded by COQ3-8) catalyze C-hydroxylations, decarboxylation, Omethylations, and C-methylation to synthesize Q [1,2].

Q distribution is not uniform among different tissues and organs, indicating that $\mathrm{Q}$ levels are adapted to the particular physiology of the tissue. Since $Q$ is rapidly broken down, as reflected in its short half-life, actual levels of $\mathrm{Q}$ in tissues are likely determined by a coordinated balance between synthesis and degradation, both of which occur in all tissues $[1,2]$. In mice, rats and humans, maximal $Q$ concentrations are present in kidney and heart, while lower amounts can be detected in liver, brain and skeletal muscle [1,15-19]. Since Q redistribution between organs appears insignificant [2], tissue-specific mechanisms must exist to determine actual levels of $\mathrm{Q}$ in any given tissue. However, the control of $\mathrm{Q}$ distribution in tissues is not fully understood.

Since Q plays a central role in energy metabolism, alterations in Q biosynthesis may participate in adaptive responses to physiological, experimental or pathological conditions shown to modify Q levels in tissues. Q is increased under cold adaptation and with exercise, while it may be decreased by aging, at least in some tissues [2]. Calorie restriction (CR) is the most robust intervention that improves healthspan and extends lifespan in many animal models [20-22]. Thus, previous investigations have also studied putative changes of Q levels with CR. In this regard, it has been reported that long-term CR increases total Q in mitochondria from skeletal muscle, liver, heart and kidney [23,24].

Because of the complex pathway leading to $\mathrm{Q}$ synthesis, simultaneously examining $\mathrm{Q}$ levels and several $C O Q$ mRNAs or proteins in different tissues can give us novel insights to understand genetic factors which determine tissue-specific distribution of $\mathrm{Q}$ and its modulation during metabolic adaptation. However, previous studies have focused on single $C O Q$ genes under normal conditions, and data are only available for $C O Q 3$ [10], $C O Q 2$ [14] and $C O Q 7$ [25-28]. The possibility that $\mathrm{CR}$ influences $\mathrm{Q}$ biosynthesis has not yet been investigated, since none of the previous studies examining $\mathrm{Q}$ changes with $\mathrm{CR}$ were focused on $C O Q$ mRNAs or proteins. We hypothesized that specific patterns of $C O Q$ mRNA levels might be identified in tissues, and that these mRNA patterns could be modulated by CR. To test this hypothesis we systematically evaluated the profile of $\mathrm{Q}_{9}$ and $\mathrm{Q}_{10}$ and steady-state 
COQ mRNAs levels in different tissues of animals fed ad libitum (AL) or under CR. We demonstrate for the first time that muscular and non-muscular tissues display unique patterns of $m C O Q$ transcripts, and that $\mathrm{Q}$ and $C O Q$ genes are targets of $\mathrm{CR}$ in a tissuespecific way, supporting the idea that alterations of $\mathrm{Q}$ biosynthesis are part of the metabolic adaptation to CR in mice.

\section{Materials and Methods}

Unless otherwise indicated, all chemicals were purchased from Sigma (Spain).

\subsection{Animals, tissue samples and ethics statement}

A cohort of 32 ten week old C57BL/6 were used (Charles River Laboratories, Spain). Male C57BL/6 mice were bred and raised in a vivarium at the Centro Andaluz de Biología del Desarrollo (CABD) under a 12h light/dark cycle (8:00 AM-8:00 PM) under controlled conditions of temperature $\left(22 \pm 3^{\circ} \mathrm{C}\right)$ and humidity. The animals were fed an AIN93G diet. Food intake was measured during 1 month to determine the average amount of food consumed per day. At 3 months of age, animals were randomly divided into AL (95\% of average diary intake) or CR (60\% average diary intake) groups. Filtered and acidified water was available ad libitum for all groups and food was replaced with every day between 8:00-9:00 am. Animals were fed for 1 month under these conditions, and then sacrificed after an 18 hour fast by cervical dislocation. Samples from liver, kidney, brain, skeletal muscle (gastrocnemius) and heart were taken, frozen in liquid nitrogen, and stored at $-80^{\circ} \mathrm{C}$ for later analysis. Animals were handled in accordance with the Pablo de Olavide University Ethical Committee rules, and the 86/609/EEC Directive on the protection of animals used for experimental and other scientific purposes.

\subsection{Quantification of steady-state levels of $C O Q$ transcripts}

Quantification of mRNA steady-state copy number was carried out by quantitative real time RT-PCR (qrtRT-PCR), where samples were run against synthetic standards. Total RNA was obtained from tissues using the Absolutely RNA RT-PCR Miniprep Kit (Stratagene, La Jolla, CA) and then reverse transcribed using the cDNA First Strand Synthesis kit (MRI Fermentas, Hanover, MD). Primers were selected using genomic sequences obtained from Genbank (National Center for Biotechnology Information (NCBI)) and Primer 3 software [29]. Specific primer sequences for $C O Q$ and housekeeping genes (glyceraldehyde-3phosphate dehydrogenase $-m G A P D H$, hypoxanthine ribosyltransferase $-m H P R T$, and $18 \mathrm{~S}$ ribosomal RNA - m18S) measured in this study, with indication of GenBank accession numbers and product sizes, are given in Table I.

Primers were used in a standard PCR with cDNA from the tissue of interest as template using the $2 \times$ Master Mix PCR reagent (MRI Fermentas). Products were run on agarose gels to confirm that only one band was amplified and no primer dimers were formed. PCR products were then column-purified (QIAGEN, Valencia, CA) and sequenced to confirm target specificity. The concentration of purified products generated by standard PCR was then determined using Molecular Probe's Picogreen DNA quantification kit, and serial dilutions of PCR products were carried out to obtain standards containing $10^{1}, 10^{2}, 10^{3}, 10^{4}$, $10^{5}, 10^{6}$ and $10^{8}$ copies of synthetic template. To determine the starting copy number of cDNA, samples were amplified by qrtRT-PCR using SYBR PCR Master Mix (Bio-Rad Laboratories, Hercules, CA). Thermocycling and fluorescence detection was performed according to standard protocols using a Bio-Rad real-time PCR machine. The signal obtained from a given tissue cDNA was compared with that of a standard curve run on the same plate. In addition, total RNA samples that were not reverse transcribed and a no-DNA 
control were run on each plate to control for genomic DNA contamination and to monitor potential exogenous contamination, respectively.

To determine if the selected housekeeping genes were appropriate as internal controls, the stability of expression was calculated using the GeNorm 3.3 Visual basic application for Microsoft Excel (http://medgen.ugent.be/ jvdesomp/genorm/) to calculate the average pairwise variation of a particular gene with all other control genes ( $M$ value) as previously developed and validated [30]. In our study, calculation of the $M$ values for the three control genes assessed revealed that $m G A P D H$ and $m 18 S$ levels were the least stable under all conditions. Therefore, $M$ values were recalculated using $m H P R T$ where all $M$ values were $<1.5$. Therefore, the copy numbers for this gene within each sample were used as normalization factors (NF). Results were then reported as [median (minimum-maximum) of $C O Q$ genes copy number minus background] / NF.

\subsection{Lipid extraction and $Q$ quantification}

A total lipid fraction was obtained from the tissues (about $30 \mathrm{mg}$ fresh weight) by homogenization in $90 \mu \mathrm{l}$ of Hank's solution to which $10 \mu \mathrm{l}$ of $10 \%$ SDS had been added to facilitate disruption of the membranes. Afterwards, two volumes of $95 \%$ ethanol-5\% isopropanol were added and the mixture was vigorously vortexed. Q was recovered from SDS-alcoholic solution by extraction with five volumes of hexane. After hexane evaporation under vacuum, the lipid extract was dissolved in a 1:1 mixture of methanol and $n$-propanol and then used for quantification of $\mathrm{Q}_{9}$ and $\mathrm{Q}_{10}$ by reversed-phase HPLC separation with a C18 column $(25 \times 0.45 \mathrm{~cm}, 5 \mu \mathrm{m}$ particle size $)$.

HPLC separation was accomplished at $1 \mathrm{ml} / \mathrm{min}$ with a mobile phase composed of a mixture of methanol and $n$-propanol (1:1) containing lithium perchlorate $(2.12 \mathrm{~g} / \mathrm{L})$. Monitoring was carried out with a Coulochem II electrochemical detector (ESA, Chelmsford, MA) fitted with a Model 5010 analytical cell with the electrodes set at potentials of $-500 \mathrm{mV}$ and +300 $\mathrm{mV}$. Quinones were detected from the signal obtained at the second electrode. Concentrations were calculated by integration of peak areas and comparison with external standards (Sigma, Madrid, Spain).

\subsection{SDS-PAGE and immunodetection of Coq2p and Coq3p}

For immunodetection of Coq2p and Coq3p polypeptides, protein (about $100 \mu \mathrm{g}$ ) was denatured by heating at $45^{\circ} \mathrm{C}$ during $15 \mathrm{~min}$ in SDS-dithiothreitol loading buffer (10\% sucrose, $2 \mathrm{mM}$ EDTA, $1.5 \%$ (w/v) SDS, $20 \mathrm{mM}$ dithiothreitol, $0.01 \%$ (w/v) bromophenol blue and $60 \mathrm{mM}$ Tris- $\mathrm{HCl}$ (pH 6.8)) containing $1 \mathrm{mM}$ PMSF and $20 \mu \mathrm{g} / \mu \mathrm{l}$ each of chymostatin, leupeptin, antipain and pepstatin A. Proteins were separated by SDS-PAGE (10\% acrylamide) and then transferred to nitrocellulose sheets. Blots were stained with Ponceau S for visualization of protein lanes. Density of staining with Ponceau's was used as a control for protein loading as described [31]. Immunostaining of western blots was carried out with chicken polyclonal anti-sera raised against the protein of interest and diluted at 1:2000. A horseradish peroxidase-conjugated anti-chicken IgG secondary antibody (Sigma) diluted at 1:5000 was used to reveal binding sites by enhanced chemiluminiscence. Photographic films and Ponceau S-stained blots were scanned in a GS-800 calibrated densitometer (Bio-Rad) to obtain digital images. Quantification of intensity reaction was carried out using Quantity One software (Bio-Rad). Data obtained from quantification of stained bands (in arbitrary units) were normalized to that of the corresponding lane stained with Ponceau $\mathrm{S}$ in order to correct for any difference in protein loading between samples. 


\subsection{Statistical analysis}

For gene expression and Q quantification studies, samples from all conditions within an experiment were processed at the same time, and therefore the in vivo effects of diet were assessed by Student's $t$ test ( $v s$. corresponding controls). The effects of diet on different tissues in C57BL/6 mice were assessed by one-way ANOVA followed by analysis of significant differences with Tukey's test for multiple comparisons. In case this test was found inappropriate for our purposes we used Duncan's non-parametric test. $P<0.05$ was considered significant. All values are expressed as mean \pm SEM. All statistical analyses were performed using the SPSS 11.0 software package (Chicago, USA) and STATISTICA 8.0. $P$ values less than 0.05 were considered significant.

\section{Results and Discussion}

\subsection{Ubiquinone distribution in mouse tissues}

We first evaluated Q distribution in different mouse tissues. For this study we chose both mitotic (liver, kidney) and postmitotic (brain, skeletal muscle, heart) tissues and organs. As depicted in Figure 1A, the highest concentration of $\mathrm{Q}_{9}$ on a protein basis was found in kidney, followed by heart, liver, brain and skeletal muscle. In the case of $\mathrm{Q}_{10}$, the order (from maximal to minimal Q concentration) was kidney, heart, brain, liver, and skeletal muscle (Figure 1B). Differences in Q distribution among tissues were very high, which agrees with previous reports for the same tissues and organs obtained from mice [16-18] or rats [19]. For instance, when we compared kidney versus skeletal muscle, differences could be as high as 20-fold in the case of $\mathrm{Q}_{9}$ and 100-fold in the case of $\mathrm{Q}_{10}$. Lower content of $\mathrm{Q}$ in gastrocnemius muscle than in heart was expected since gastrocnemius contains abundant fast-twitch glycolytic fibres and much less mitochondria than heart [32]. In accordance, differences between skeletal muscle and heart are much lower when measuring $\mathrm{Q}_{9}$ and $\mathrm{Q}_{10}$ in isolated mitochondria $[18,19,23]$.

$\mathrm{Q}_{9} / \mathrm{Q}_{10}$ ratios also displayed significant variability among tissues and organs in the mouse. Highest $\mathrm{Q}_{9} / \mathrm{Q}_{10}$ ratios were observed in liver and skeletal muscle (mean values of about 19 and 15, respectively), although inter-individual variability was also very high. A lower $\mathrm{Q}_{9} /$ $\mathrm{Q}_{10}$ ratio (mean value of 8.6) was found in heart, which also showed lower individual variability. Kidney and brain exhibited both the lowest $\mathrm{Q}_{9} / \mathrm{Q}_{10}$ ratios (mean values of 4.6 and 2.7, respectively) and the lowest variability among individuals, particularly in the case of brain, where all $\mathrm{Q}_{9} / \mathrm{Q}_{10}$ values were contained within an extremely narrow range (Figure 1C). This observation supports the idea that the homeostatic range for $Q$ isoforms varies among tissues and organs, and the maintenance of a given $\mathrm{Q}_{9} / \mathrm{Q}_{10}$ ratio may be important for proper function of organs, particularly brain, showing a relatively high $\mathrm{Q}_{10}$ content.

\subsection{Steady-state levels of $C O Q$ transcripts in tissues}

One of our major aims was to systematically evaluate steady-state levels of $C O Q$ transcripts in different mouse tissues. No previous study has applied qrtRT-PCR to provide a reliable estimate of steady-state levels of several $C O Q$ transcripts. Previous studies have also not investigated the relationship between levels of several $C O Q$ transcripts and $\mathrm{Q}$ distribution in the same tissues. We focused our study on genes encoding proteins of known or putative function in $\mathrm{Q}$ biosynthesis for which inactivating mutations that result in Q deficiency have been observed in humans [2]. These included $m P D S S 1$ and $m P D S S 2$, the two subunits of polyprenyl diphosphate synthase; $m C O Q 2$, the polyprenyl-4-hydroxybenzoate transferase which catalyzes the first enzymatic step that is specific for $\mathrm{Q}$ biosynthesis, and $m C O Q 8$ / ADCK3, a putative kinase [1,2]. In addition, we also included in our study two additional $C O Q$ genes with well-established function in $\mathrm{Q}$ biosynthesis: $m C O Q 3$ and $m C O Q 7$. $C O Q 3$ encodes 2,3-dihydroxy-5-polyprenylbenzoate-methyl transferase, which is responsible for 
the two $O$-methylations steps in the production of $\mathrm{Q}$, the last of these yielding the final product $[10,33,34]$. COQ7/Clk-1 encodes an hydroxylase which catalyzes the conversion of 5-demethoxy-Q to hydroxy-Q, the penultimate step of $\mathrm{Q}$ biosynthesis [35], and plays a prominent role in determining life span in vertebrate and invertebrate animal models [36].

We demonstrate here for the first time that tissues can be grouped according to steady-state levels of $C O Q$ transcripts (Figure 2) into two basic patterns: muscular and non muscular. Among the transcripts studied, $m C O Q 7$ was the most abundant in gastrocnemius and heart, followed by $m C O Q 8, m C O Q 2, m P D S S 2, m P D S S 1$ and $m C O Q 3$. However, despite exhibiting a similar pattern of $m C O Q$ transcripts, the two muscular tissues differed by almost one order of magnitude in Q levels (see Figures 1 and 2). The striking similarity between the transcript patterns of gastrocnemius and heart supports the idea that the difference of $\mathrm{Q}$ content is due to post-transcriptional mechanisms which drive $\mathrm{Q}$ biosynthesis rate, the amount of mitochondria, and probably the catabolic rates of $\mathrm{Q}$ degradation [2]. The two mitotic organs studied, liver and kidneys, displayed an almost identical pattern of steady-state $C O Q$ transcripts levels. Maximal abundance was observed for $m C O Q 2$, followed by $m C O Q 7, m C O Q 8, m P D S S 1, m P D S S 2$, and $m C O Q 3$. The pattern of $C O Q$ transcripts in brain was similar to those of liver and kidneys, although the absolute number of copies of $C O Q$ transcripts was lower (Figure 2). Of note, compared with other $m C O Q$ mRNAs, steady-state levels of $m C O Q 3$ transcripts were very low in non muscular tissues.

Very few studies have addressed the tissue distribution of $C O Q$ transcripts, and none have analyzed simultaneously several $C O Q$ genes by means of a quantitative and reliable technique, such as qrtRT-PCR. Previous studies have focused on single $C O Q$ genes, and data are only available for $C O Q 2, C O Q 3$, and $C O Q 7$. Forsgren et al. [14] cloned the human $C O Q 2$ gene and studied tissue distribution of $h C O Q 2$ transcript using dot blot with a radioactive probe in a commercial array for human mRNA. Maximal levels of $h C O Q 2$ mRNA were detected in muscle and heart tissue, which agrees with our results. However, the abundance of $h C O Q 2$ transcript was considerable lower in kidney, as well as in other non muscular tissues. Here we show that $m C O Q 2$ transcripts can be found at comparable levels in kidney and muscular tissues. This discrepancy could be due to species specificity (human $v s$ mouse). The study of Marbois et al. [10] was focused on tissue distribution of COQ3 mRNA in the rat, using Northern blot with a radioactive probe. Steady-state levels of COQ3 mRNA were studied in brain, heart, kidney, liver, skeletal muscle and testis. Rat COQ3 mRNA was particularly abundant in testis, heart and thigh muscle, followed in order of abundance by kidney, brain and liver, which agrees with our study. Finally, a number of studies have addressed the distribution of $C O Q 7 \mathrm{mRNA}$ in several human and mouse tissues. These studies have demonstrated that $h C O Q 7 \mathrm{mRNA}$ is found predominantly in heart and skeletal muscle, whereas very low levels are present in brain, placenta, liver, kidney, pancreas and lung [25,37]. In mice, $m C O Q 7 \mathrm{mRNA}$ was particularly abundant in heart, skeletal muscle and kidney [27], which also agrees with our results.

We report here that the mRNAs encoding for the two subunits of the polyprenyl diphosphate synthase ( $m P D S S 1$ and $m P D S S 2$ ) were particularly abundant in muscular tissues. PDSS1 and $P D S S 2$ have been proposed to play an important role in determining $\mathrm{Q}$ levels because the polyprenyl diphosphate synthase is the branch-point enzyme that utilizes FPP in the terminal part of $\mathrm{Q}$ biosynthesis, a process which is considered limited by the availability of polyisoprenoid chain precursor [2]. However, steady-state levels of $m P D S S 1$ and $m P D S S 2$ transcripts were similar in kidney and liver, two organs whose Q content differed substantially (see Figure 1), suggesting the existence of post-transcriptional levels of regulation. It is also possible that a limited amount of $m P D S S 1$ and $m P D S S 2$ transcripts is sufficient to provide enough polyisoprenoid chain precursor in these two mitotic organs, the 
higher concentration of Q in kidney being determined by a higher amount of mitochondria [2]. Transgenic mice harboring an overexpression of mutated PDSS2 isoform showed a kidney defect associated with $\mathrm{Q}$ deficiency that was partially rescued by $\mathrm{Q}$ supplementation [13].

\subsection{Tissue patterns of Coq2 and Coq3 polypeptides}

Of note, $m C O Q 3$ transcripts varied substantially among the different tissues irrespective of their Q levels (see Figures 1 and 2). The lack of correlation between $m C O Q 3$ transcripts and $\mathrm{Q}$ levels in tissues has been explained on the basis of the existence of post-transcriptional controls [10]. However, no study has been designed to date to test this hypothesis. Thus, we were interested in analyzing tissue levels of mCoq3 polypeptide to investigate if protein levels followed those of mRNA. Our study at the protein level also included mCoq2p. Although increased in kidney, heart and skeletal muscle, steady-state levels of mCOQ2 in tissues were more homogeneous than those of $\mathrm{mCOQ3}$ (see Figure 2).

As depicted in Figure 3, mCoq2p levels were higher in tissues and organs which showed the highest levels of $m C O Q 2$ transcripts. Maximal levels of Coq2p were detected in heart and kidney, the two organs showing the highest levels of $\mathrm{Q}$, followed by skeletal muscle. The lowest levels of mCoq2 $p$ were detected in brain and liver, which also showed lower steadystate levels of $m C O Q 2$ transcripts. With respect to mCoq3p, maximal levels were detected in heart, while this polypeptide was found at significantly lower amounts in liver, kidney, skeletal muscle and brain. It is noteworthy that differences between the latter four tissues in terms of steady-state levels of $m C O Q 3$ transcripts were of up to 3 orders of magnitude (if we compare skeletal muscle versus brain) whereas similar levels of mCoq3p were found in these tissues, demonstrating a strong regulation at a post-transcriptional level, as previously suggested [10]. The relatively low level of mCoq3p in kidney is very interesting because this organ showed by far the highest levels of $\mathrm{Q}_{9}$ and $\mathrm{Q}_{10}$. Although Coq3p catalyzes two steps in $\mathrm{Q}$ biosynthesis, the last of them yielding the final product [10,33,34], the low levels of $m C O Q 3$ RNA and mCoq3p in kidney is consistent with a non limiting role for Coq3p in Q biosynthesis. In accordance, it has been suggested that $\mathrm{Q}$ levels in tissues are regulated at the initial steps in the terminal part of $\mathrm{Q}$ biosynthesis. Competitive inhibition of Coq2p by $p$ hydroxybenzoate analogues readily decreases $Q$ levels in cellular systems [38,39], supporting an important role for Coq2p in the overall regulation of $Q$ synthesis. Furthermore, there was no correlation between levels of Coq7p (which catalyzes the penultimate step of $\mathrm{Q}$ biosynthesis) and those of $\mathrm{Q}$ in a mouse model of transgene $m C O Q 7$ expression [28]. However, the Coq7 reaction is apparently a point of regulation of $\mathrm{Q}$ biosynthesis pathway in yeast by post-transcriptional modification of either Coq7p or any component of the biosynthesis pre-complex [40].

\subsection{The effect of calorie restriction on $Q$ tissue levels}

One month of $40 \% \mathrm{CR}$ produced changes in the absolute levels of $\mathrm{Q}$ in muscular tissues (Figure 1). An increase of both $\mathrm{Q}_{9}$ and $\mathrm{Q}_{10}$ was detected in skeletal muscle, whereas a decrease of $\mathrm{Q}_{9}$ with no change in $\mathrm{Q}_{10}$ was detected in heart. In addition, the $\mathrm{Q}_{9} / \mathrm{Q}_{10}$ ratio was increased in kidney but decreased in heart. Previous reports have shown that long-term $\mathrm{CR}$ increased $\mathrm{Q}_{9}$ content of mitochondria isolated from skeletal muscle [23], liver, heart and kidney [24], although another study reported that CR induced a decrease of $\mathrm{Q}_{9}$ and $\mathrm{Q}_{10}$ in liver mitochondria [41]. The increase of $\mathrm{Q}_{9}$ by $\mathrm{CR}$ in skeletal muscle mitochondria [23] agrees with our results, although we also observed an increase of $\mathrm{Q}_{10}$, and these changes were detected very early, after one month of CR. Our results are in agreement with Bevilacqua et al. [42], who demonstrated that skeletal muscle (but not liver) mitochondria are rapidly adapted to short-term (2-wk and 2-mo) $\mathrm{CR}$ in the rat with a significant decrease of ROS generation [43]. It is possible that CR effects on Q in liver are a late event since life- 
long $\mathrm{CR}$ attenuated the increase of $\mathrm{Q}_{9} / \mathrm{Q}_{10}$ ratio in rat liver plasma membrane from aged rats [44].

Very few pharmacological treatments or physiological conditions are known to produce significant increases of $\mathrm{Q}$ in tissues, and most of them are related with oxidative stress conditions. An early work described increases in the contents of $Q$ in liver and, to some extent, in kidney and muscle of rats treated with peroxisome proliferators, without modifying cholesterol levels [45]. More recently, it was reported that camptothecin and other chemotherapeutic drugs, such as etoposide, doxorubicin, and methotrexate, increased $\mathrm{Q}_{10}$ levels in tumour cells as part of an antioxidant response [46]. Finally, the mono and diepoxy derivatives of $\alpha$ - $\gamma$-tocotrienols are strong stimulators of $Q$ biosynthesis [2]. The $\mathrm{CR}$-induced increase of $\mathrm{Q}_{9}$ and $\mathrm{Q}_{10}$ in skeletal muscle is unique because it is associated with decreased oxidative stress [42]. In addition to alterations in the abundance of $m C O Q$ transcripts (see below), a more reduced status might lead to higher Q levels in skeletal muscle due to reduced oxidative degradation.

The effects of CR on $\mathrm{Q}$ levels and $\mathrm{Q}_{9} / \mathrm{Q}_{10}$ ratio in heart are noteworthy because these modifications might be associated with alterations in mitochondrial function. Interestingly, ubisemiquinone-derived ROS are believed to be involved in $\mathrm{Ca}^{2+}$-stimulated permeabilization of mitochondria due to the opening of the permeability transition pore (PTP) [47], and quinones are well known modulators of the PTP [48,49]. Interestingly, short-term ( 2 mo) CR produced a small (14\%) decrease in ROS production by heart ventricular subsarcolemmal mitochondria isolated from 6 mo male F344 rats [50], and counteracted the age-related loss in their $\mathrm{Ca}^{2+}$ retention capacity [51]. It is tempting to speculate that the CR-induced changes of the $\mathrm{Q}$ system we show here could be related with some of the beneficial effects of CR on the mitochondrial physiology in heart. However, it has to be acknowledged that CR produced opposite effects on Q levels in kidney, which points to the existence of different mechanisms of regulation in this mitotic organ compared with heart.

The $\mathrm{Q}_{9} / \mathrm{Q}_{10}$ ratio is determined by the polyisoprenoid substrate available for the reaction catalyzed by the polyprenyl 4-hydroxybenzoate transferase. The actual products of the trans-prenyltransferase activity (nona- or decaprenylpyrophosphate) are determined by the ratio between FPP and IPP, giving more decaprenylpyrophosphate in the presence of high IPP- $\mathrm{Mg}^{2+}[52]$. Thus, our observations that $\mathrm{CR}$ increased $\mathrm{Q}_{9} / \mathrm{Q}_{10}$ ratio in kidney but decreased it in heart might indicate the existence of alterations in IPP/FPP ratio under CR conditions.

\subsection{Effect of calorie restriction on steady-state $C O Q$ transcripts and Coq2 and Coq3 polypeptides}

We next studied how calorie restriction affected steady-state levels of $C O Q$ transcripts in tissues. As depicted in Figure 4, the abundance of $m C O Q$ transcripts was affected by CR in a tissue-specific manner. The response of the two mitotic tissues to $\mathrm{CR}$ included a modest increase of some $m C O Q$ transcripts: $m C O Q 2, m C O Q 3, m C O Q 7$ and $m C O Q 8$ in liver, and $m C O Q 2$ and $m C O Q 7$ in kidney. If we compare these results with those obtained for $\mathrm{Q}$ levels, we can conclude that the limited changes of mRNAs detected in liver and kidney were not sufficient to produce significant alterations of Q levels. No changes in $m P D S S 1$ or $m P D S S 2$ transcripts were observed in kidney from CR mice. A mutation in PDSS1 has been demonstrated to decrease significantly $\mathrm{Q}_{10}$ without affecting $\mathrm{Q}_{9}$ levels in humans [53].

Muscular tissues were affected by CR in a different way. In skeletal muscle $m P D S S 2$ was increased, whereas $C O Q 7$ was decreased. The increase of $m P D S S 2$ in skeletal muscle coincided with a significant increase of $\mathrm{Q}_{9}$ and $\mathrm{Q}_{10}$ levels (see above). Camptothecin- 
induced increase of $\mathrm{Q}_{10}$ levels in cellular systems was associated with up-regulation of Coq7p expression, as part of an antioxidant response [46]. Increase of $\mathrm{Q}_{10}$ biosynthesis by chemotherapeutic drugs is dependent on NF- $\mathrm{KB}$ that binds specifically to two $\mathrm{\kappa B}$ binding sites present in the 5'-flanking region of the $C O Q 7$ gene, inducing both the $C O Q 7$ expression and $\mathrm{Q}_{10}$ biosynthesis [54]. Here, we show that the CR-induced increase of $\mathrm{Q}$ levels in skeletal muscle is not dependent on increased abundance of $m C O Q 7$ mRNA but, on the contrary, decreased steady-state levels of $m C O Q 7$ with $\mathrm{CR}$ were found in this tissue. The fact that CR can increase both steady-state levels of $m P D S S 2$ and total Q in skeletal muscle may be of importance because skeletal muscle is one of the specific sites of Q deficiency and tissue damage caused by a mutation in the PDSS2 gene in humans [55]. In heart, the general response was a decrease in many of the $C O Q$ transcripts analyzed, except for $C O Q 7$, which showed a slight increase. The decrease of $\mathrm{Q}_{9}$ with $\mathrm{CR}$ in heart is consistent with significant decreases of $m P D S S 2, m C O Q 2$, and $m C O Q 8$ transcripts. A trend towards lower levels was also observed for $m P D S S 1$ and $m C O Q 3$ in heart from CR mice, although differences were not statistically significant. Remarkably, no change in steady-state levels of any of the $C O Q$ transcripts was observed in brain, which coincided with the lack of changes elicited by $\mathrm{CR}$ in $\mathrm{Q}$ levels.

We also studied putative variations in the amount of Coq 2 and Coq3 polypeptides induced by CR. For this analysis we only included the organs or tissues that exhibited some change associated with CR, either in $\mathrm{Q}$ or $C O Q$ transcripts levels. As depicted in Figure 5, the general tendency was either no change, or decreases of Coq2 and Coq3 polypeptides with $\mathrm{CR}$. Although Coq $3 p$ was decreased by CR in kidney, Coq2 $p$ was unchanged. As stated above, steady-state abundance of $m C O Q 3$ or Coq3p do not correlate with $\mathrm{Q}$ levels, and the possibility exists that relatively low levels of Coq3p are sufficient to provide enough $Q$ biosynthesis. The lack of CR-induced changes for $m C O Q 2$ and $m C O Q 3$ transcripts in skeletal muscle is consistent with the absence of changes at the level of protein, which agrees with the idea that the increase of Q levels by short-term CR in skeletal muscle is regulated at an early point, most likely by the availability of polyisoprenoid chain precursor [2] and/or by a less oxidant status [42] which leads to decreased oxidative degradation. In heart, the decrease in most $m C O Q$ transcripts coincided with decreases of Coq2p and Coq3p, suggesting that lower levels of $\mathrm{Q}_{9}$ in heart after 1 mo of CR may be the result of decreased biosynthesis.

In summary we demonstrate for the first time that muscular and non-muscular tissues display unique patterns of $m C O Q$ transcripts, and that $\mathrm{Q}$ and $C O Q$ genes are targets of $\mathrm{CR}$ in a tissue-specific way, supporting the idea that alterations of $\mathrm{Q}$ biosynthesis are part of the metabolic adaptation to $\mathrm{CR}$ in mice.

\section{Acknowledgments}

This work was supported by NIH grant 1R01AG028125-01A1 (to JJR, PN and JMV), Junta de Andalucía Proyectos de Excelencia grant CVI-00648 (to PN), Junta de Andalucía Proyectos de Excelencia grant P09CVI-4887 (to JMV), Junta de Andalucía Proyectos Internacionales grant (to JMV), and BIO-276 (Junta de Andalucía and the University of Córdoba, to JMV). CP was funded by CVI-00648 grant. We thank Raúl Luque for providing housekeeping genes sequences and for transmitting us his experience with qrtRT-PCR. We thank Almudena Velázquez for handling of laboratory animals.

\section{List of non standard abbreviations}
AL
Ad libitum
CR
calorie restriction
FPP
farnesyl pyrophosphate 

IPP isopentenyl pyrophosphate
NF normalization factor
PTP permeability transition pore
Q coenzyme Q, ubiquinone
UCPs mitochondrial uncoupling proteins

\section{References}

[1]. Turunen M, Olsson J, Dallner G. Metabolism and function of coenzyme Q. Biochim. Biophys. Acta. 2004; 1660:171-199. [PubMed: 14757233]

[2]. Bentinger M, Tekle M, Dallner G. Coenzyme Q - Biosynthesis and functions. Biochem. Biophys. Res. Commun. 2010; 396:74-79. [PubMed: 20494114]

[3]. González-Aragón D, Ariza J, Villalba JM. Dicoumarol impairs mitochondrial electron transport and pyrimidine biosynthesis in human myeloid leukemia HL-60 cells. Biochem. Pharmacol. 2007; 73:427-439. [PubMed: 17123468]

[4]. López-Martín JM, Salviati L, Trevisson E, Montini G, DiMauro S, Quinzii C, Hirano M, Rodríguez-Hernández A, Cordero MD, Sánchez-Alcázar JA, Santos-Ocaña C, Navas P. Missense mutation of the $C O Q 2$ gene causes defects of bioenergetics and de novo pyrimidine synthesis. Hum. Mol. Genet. 2007; 16:1091-1097. [PubMed: 17374725]

[5]. Villalba JM, Navarro F, Córdoba F, Serrano A, Arroyo A, Crane FL, Navas P. Coenzyme Q reductase from liver plasma membrane: purification and role in transplasma membrane electron transport. Proc. Natl. Acad. Sci. USA. 1995; 92:4887-4892. [PubMed: 7761418]

[6]. Jarmuszkiewicz W, Navet R, Alberici LC, Douette P, Sluse-Goffart CM, Sluse FE, Vercesi AE. Redox state of endogenous coenzyme Q modulates the inhibition of linoleic acid-induced uncoupling by guanosine triphosphate in isolated skeletal muscle mitochondria. J. Bioenerg. Biomembr. 2004; 36:493-502. [PubMed: 15534396]

[7]. Papucci L, Schiavone N, Witort E, Donnini M, Lapucci A, Tempestini A, Formigli L, ZecchiOrlandini S, Orlandini G, Carella G, Brancato R, Capaccioli S. Coenzyme Q 10 prevents apoptosis by inhibiting mitochondrial depolarization independently of its free radical scavenging property. J. Biol. Chem. 2003; 278:28220-28228. [PubMed: 12736273]

[8]. Villalba JM, Navas P. Plasma membrane redox system in the control of stress-induced apoptosis. Antiox. Redox Signal. 2000; 2:213-230.

[9]. Elmberger PG, Kalèn A, Appelkvist E-L, Dallner G. In vitro and in vivo synthesis of dolichol and other main mevalonate products in various organs of the rat. Eur. J. Biochem. 1987; 168:1-11. [PubMed: 3665910]

[10]. Marbois BN, Xia Y-R, Lusis AJ, Clarke CF. Ubiquinone biosynthesis in eukaryotic cells: Tissue distribution of mRNA encoding 3,4-dihydroxy-5-polyprenylbenzoate methyltransferase in the rat and mapping of the COQ3 gene to mouse chromosome 4. Arch. Biochem. Biophys. 1994; 313:83-88. [PubMed: 8053692]

[11]. Villalba JM, Parrado C, Santos-González M, Alcaín FJ. Therapeutic use of coenzyme $\mathrm{Q}_{10}$ and coenzyme $\mathrm{Q}_{10}$-related compounds and formulations. Expert. Opin. Invest. Drugs. 2010; 19:535554.

[12]. Saiki R, Nagata A, Kainou T, Matsuda H, Kawamukai M. Characterization of solanesyl and decaprenyl diphosphate synthases in mice and humans. FEBS J. 2005; 272:5606-5622. [PubMed: 16262699]

[13]. Peng M, Falk MJ, Haase VH, King R, Polyak E, Selak M, Yudkoff M, Hancock WW, Meade R, Saiki R, Lunceford AL, Clarke CF, Gasser DL. Primary coenzyme Q deficiency in Pdss2 mutant mice causes isolated renal disease. PLoS Genet. 2008; 4:e1000061. doi:10.1371/journal.pgen. 1000061. [PubMed: 18437205] 
[14]. Forsgren M, Attersand A, Lake S, Grünler J, Swiezewska E, Dallner G, Climent I. Isolation and functional expression of human $C O Q 2$, a gene encoding a polyprenyl transferase involved in the synthesis of CoQ. Biochem. J. 2004; 382:519-526. [PubMed: 15153069]

[15]. Aberg F, Appelkvist EL, Dallner G, Ernster L. Distribution and redox state of ubiquinones in rat and human tissues. Arch. Biochem. Biophys. 1992; 295:230-234. [PubMed: 1586151]

[16]. Lass A, Forster MJ, Sohal RS. Effects of coenzyme $Q_{10}$ and $\alpha$-tocopherol administration on their tissue levels in the mouse: Elevation of mitochondrial $\alpha$-tocopherol by coenzyme $\mathrm{Q}_{10}$. Free Radic. Biol. Med. 1999; 26:1375-1383. [PubMed: 10401600]

[17]. Tang PH, Miles MV, Miles L, Quinlan J, Wong B, Wenisch A, Bove K. Measurement of reduced and oxidized coenzyme $\mathrm{Q}_{9}$ and coenzyme $\mathrm{Q}_{10}$ levels in mouse tissues by HPLC with coulometric detection. Clin. Chim. Acta. 2004; 341:173-184. [PubMed: 14967174]

[18]. Sohal RS, Kamzalov S, Sumien N, Ferguson M, Rebrin I, Heinrich KR, Forster MJ. Effect of coenzyme $\mathrm{Q}_{10}$ intake on endogenous coenzyme Q content, mitochondrial electron transport chain, antioxidative defenses, and life span of mice. Free Radic. Biol. Med. 2006; 40:480-487. [PubMed: 16443163]

[19]. Kwong LK, Kamzalov S, Rebrin I, Bayne A-CV, Jana CK, Morris P, Forster MJ, Sohal RS. Effects of coenzyme $\mathrm{Q}_{10}$ administration on its tissue concentrations, mitochondrial oxidant generation, and oxidative stress in the rat. Free Radic. Biol. Med. 2002; 33:627-638. [PubMed: 12208349]

[20]. Hursting SD, Lavigne JA, Berrigan D, Perkins SN, Barrett JC. Calorie restriction, aging, and cancer prevention: mechanisms of action and applicability to humans. Annu. Rev. Med. 2003; 54:131-152. [PubMed: 12525670]

[21]. Pollak M. Do cancer cells care if their host is hungry? Cell Metab. 2009; 9:401-403. [PubMed: 19416708]

[22]. Witte AV, Fobker M, Gellner R, Knecht S, Floel A. Caloric restriction improves memory in elderly humans. Proc. Natl. Acad. Sci. USA. 2009; 106:1255-1260. [PubMed: 19171901]

[23]. Lass A, Kwong L, Sohal RS. Mitochondrial coenzyme Q content and aging. BioFactors. 1999; 9:199-205. [PubMed: 10416032]

[24]. Kamzalov S, Sohal R. Effect of age and caloric restriction on coenzyme Q and $\alpha$-tocopherol levels in the rat. Exp. Gerontol. 2004; 39:1199-1205. [PubMed: 15288694]

[25]. Asaumi S, Kuroyanagi H, Seki N, Shirasawa T. Orthologues of the Caenorhabditis elegans longevity gene $c l k-1$ in mouse and human. Genomics. 1999; 58:293-301. [PubMed: 10373327]

[26]. Takahashi M, Asaumi S, Honda S, Suzuki Y-I, Nakai D, Kuroyanagi H, Shimizu T, Honda Y, Shirasawa T. Mouse coq7/clk-1 orthologue rescued slowed rhythmic behavior and extended life span of clk-1 longevity mutant in Caenorhabditis elegans. Biochem. Biophys. Res. Commun. 2001; 286:534-540. [PubMed: 11511092]

[27]. Jiang N, Levavasseur F, McCright B, Shoubridge EA, Hekimi S. Mouse CLK-1 is imported into mitochondria by an unusual process that requires a leader sequence but no membrane potential. J. Biol. Chem. 2001; 276:29218-29225. [PubMed: 11387338]

[28]. Nakai D, Shimizu T, Nojiri H, Uchiyama S, Koike H, Takahashi M, Hirokawa K, Shirasawa T. Coq7/clk1 regulates mitochondrial respiration and the generation of reactive oxygen species via coenzyme Q. Aging Cell. 2004; 3:273-281. [PubMed: 15379851]

[29]. Rozen S, Skaletsky H. Primer3 on the WWW for general users and for biologist programmers. Methods Mol. Biol. 2000; 132:365-386. [PubMed: 10547847]

[30]. Vandesompele J, De Preter K, Pattyn F, Poppe B, Van Roy N, De Paepe A, Speleman F. Accurate normalization of real-time quantitative RT-PCR data by geometric averaging of multiple internal control genes. Genome Biol. 2002; 3 RESEARCH0034.

[31]. Bello RI, Alcaín FJ, Gómez-Díaz C, López-Lluch G, Navas P, Villalba JM. Hydrogen peroxide and cell density-regulated expression of cytochrome $b_{5}$ reductase in HeLa cells. J. Bioenerg. Biomembr. 2003; 35:169-179. [PubMed: 12887015]

[32]. Hamalainen N, Pette D. The histochemical profiles of fast fiber types IIB, IID and IIA in skeletal muscles of mouse, rat and rabbit. J. Histochem. Cytochem. 1993; 41:733-743. [PubMed: 8468455] 
[33]. Poon WW, Barkovich RJ, Hsu AY, Frankel A, Lee PT, Shepherd JN, Myles DC, Clarke CF. Yeast and rat Coq3 and Escherichia coli UbiG polypeptides catalyze both $O$-methyltransferase steps in coenzyme Q biosynthesis. J. Biol. Chem. 1999; 274:21665-21672. [PubMed: 10419476]

[34]. Jonassen $\mathrm{T}$, Clarke CF. Isolation and functional expression of human $C O Q 3$, a gene encoding a methyltransferase required for ubiquinone biosynthesis. J. Biol. Chem. 2000; 275:12381-12387. [PubMed: 10777520]

[35]. Stenmark P, Grünler J, Mattsson J, Sindelar PJ, Nordlund P, Berthold DA. A new member of the family of di-iron carboxylate proteins. Coq7 (clk-1), a membrane bound hydroxylase involved in ubiquinone biosynthesis. J. Biol. Chem. 2001; 276:33297-33300. [PubMed: 11435415]

[36]. Liu X, Jiang N, Hughes B, Bigras E, Shoubridge E, Hekimi S. Evolutionary conservation of the clk-1-dependent mechanism of longevity: Loss of $m c l k 1$ increases cellular fitness and lifespan in mice. Genes Dev. 2005; 19:2424-2434. [PubMed: 16195414]

[37]. Vajo Z, King LM, Jonassen T, Wilkin DJ, Ho N, Munnich A, Clarke CF, Francomano CA. Conservation of the Caenorhabditis elegans timing gene $c l k-1$ from yeast to human: a gene required for ubiquinone biosynthesis with potential implications for aging. Mammalian Genome. 1999; 10:1000-1004. [PubMed: 10501970]

[38]. González-Aragón D, Burón MI, López-Lluch G, Hermán MD, Gómez-Díaz C, Navas P, Villalba JM. Coenzyme Q and the regulation of intracellular steady-state levels of superoxide in HL-60 cells. BioFactors. 2005; 25:31-41. [PubMed: 16873928]

[39]. Forsman U, Sjöberg M, Turunen M, Sindelar PJ. 4-Nitrobenzoate inhibits coenzyme Q biosynthesis in mammalian cell cultures. Nat. Chem. Biol. 2010; 6:515-517. [PubMed: 20526342]

[40]. Padilla S, Tran UC, Jiménez-Hidalgo M, López-Martín JM, Martín-Montalvo A, Clarke CF, Navas P, Santos-Ocaña C. Hydroxylation of demethoxy-Q6 constitutes a control point in yeast coenzyme Q6 biosynthesis. Cell. Mol. Life Sci. 2009; 66:173-186. [PubMed: 19002377]

[41]. Armeni T, Principato G, Quiles JL, Pieri C, Bompadre S, Battino M. Mitochondrial dysfunctions during aging: Vitamin E deficiency or calorie restriction - Two different ways of modulating stress. J. Bioenerg. Biomembr. 2003; 35:181-191. [PubMed: 12887016]

[42]. Bevilacqua L, Ramsey JJ, Hagopian K, Weindruch R, Harper ME. Effects of short- and mediumterm calorie restriction on muscle mitochondrial proton leak and reactive oxygen species production. Am. J. Physiol. Endocrinol. Metab. 2004; 286:E852-E861. [PubMed: 14736705]

[43]. Ramsey JJ, Hagopian K, Kenny TM, Koomson EK, Bevilacqua L, Weindruch R, Harper ME. Proton leak and hydrogen peroxide production in liver mitochondria from energy-restricted rats. Am. J. Physiol. Endocrinol. Metab. 2004; 286:E31-E40. [PubMed: 14662512]

[44]. De Cabo R, Cabello R, Rios M, López-Lluch G, Ingram DK, Lane MA, Navas P. Calorie restriction attenuates age-related alterations in the plasma membrane antioxidant system in rat liver. Exp. Gerontol. 2004; 39:297-304. [PubMed: 15036389]

[45]. Aberg F, Zhang Y, Teclebrhan H, Appelkvist EL, Dallner G. Increases in tissue levels of ubiquinone in association with peroxisome proliferation. Chem. Biol. Interact. 1996; 99:205218. [PubMed: 8620569]

[46]. Brea-Calvo G, Rodríguez-Hernández A, Fernández-Ayala DJ, Navas P, Sánchez-Alcázar JA. Chemotherapy induces an increase in coenzyme $\mathrm{Q}_{10}$ levels in cancer cell lines. Free Radic. Biol. Med. 2006; 40:1293-1302. [PubMed: 16631519]

[47]. Kowaltowski AJ, Castilho RF, Vercesi AE. $\mathrm{Ca}^{2+}$-induced mitochondrial membrane permeabilization: role of coenzyme Q redox state. Am. J. Physiol. 1995; 269:C141-C147. [PubMed: 7631741]

[48]. Fontaine E, Ichas F, Bernardi P. A ubiquinone-binding site regulates the mitochondrial permeability transition pore. J. Biol. Chem. 1998; 273:25734-25740. [PubMed: 9748242]

[49]. Walter L, Nogueira V, Leverve X, Heitz MP, Bernardi P, Fontaine E. Three classes of ubiquinone analogs regulate the mitochondrial permeability transition pore through a common site. J. Biol. Chem. 2000; 275:29521-29527. [PubMed: 10889201]

[50]. Judge S, Judge A, Grune T, Leeuwenburgh C. Short-term CR decreases cardiac mitochondrial oxidant production but increases carbonyl content. Am. J. Physiol. Regul. Integr. Comp. Physiol. 2004; 286:R254-R259. [PubMed: 14592935] 
[51]. Hofer T, Servais S, Seo AY, Marzetti E, Hiona A, Upadhyay SJ, Wohlgemuth SE, Leeuwenburgh C. Bioenergetics and permeability transition pore opening in heart subsarcolemmal and interfibrillar mitochondria: Effects of aging and lifelong calorie restriction. Mech. Ageing Dev. 2009; 130:297-307. [PubMed: 19428447]

[52]. Runquist M, Ericsson J, Thelin A, Chojnacki T, Dallner G. Isoprenoid biosynthesis in rat liver mitochondria. J. Biol. Chem. 1994; 269:5804-5809. [PubMed: 8119922]

[53]. Mollet J, Giurgea I, Schlemmer D, Dallner G, Chretien D, Delahodde A, Bacq D, de Lonlay P, Munnich A, Rötig A. Prenyldiphosphate synthase, subunit 1 (PDSS1) and OH-benzoate polyprenyltransferase (COQ2) mutations in ubiquinone deficiency and oxidative phosphorylation disorders. J. Clin. Invest. 2007; 117:765-772. [PubMed: 17332895]

[54]. Brea-Calvo G, Siendones E, Sánchez-Alcázar JA, de Cabo R, Navas P. Cell survival from chemotherapy depends on NF-kappaB transcriptional up-regulation of coenzyme $Q$ biosynthesis. PLoS One. 2009; 4:e5301. [PubMed: 19390650]

[55]. Lopez LC, Schuelke M, Quinzii CM, Kanki T, Rodenburg RJ, Naini A, Dimauro S, Hirano M. Leigh syndrome with nephropathy and $\mathrm{CoQ}_{10}$ deficiency due to decaprenyl diphosphate synthase subunit 2 (PDSS2) mutations. Am. J. Hum. Genet. 2006; 79:1125-1129. [PubMed: 17186472] 


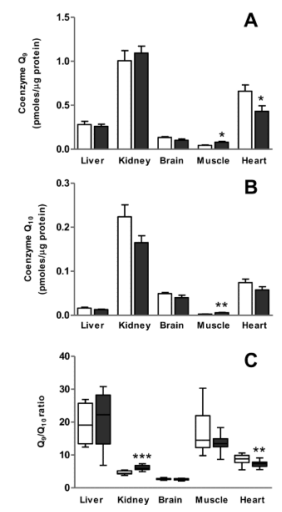

Figure 1.

Tissue distribution of $\mathrm{Q}$ homologues and $\mathrm{Q}_{9} / \mathrm{Q}_{10}$ ratio. Tissues (liver, kidney, brain, skeletal muscle and heart) were taken from 4 mo old mice that had been fed ad libitum or under 1 mo CR. Quinones were recovered by organic extraction with hexane, and separated and quantified by HPLC. A) $Q_{9}$ levels. B) $Q_{10}$ levels. C) $Q_{9} / Q_{10}$ ratio. Data are means \pm SEM $(\mathrm{n}=16)$. Significant differences between diets (ad libitum vs $\mathrm{CR})$ are indicated by asterisks (* $\mathrm{p}<0.05 ; * * \mathrm{p}<0.01 ; * * * \mathrm{p}<0.001)$. Open bars, ad libitum; Closed bars : CR. 


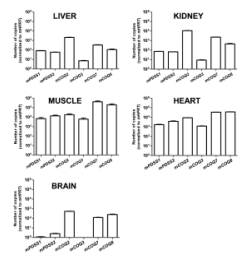

Figure 2.

Patterns of steady-state levels of $m C O Q$ transcripts in mouse tissues. RNA samples were extracted from liver, kidney, brain, skeletal muscle and heart obtained from control animals (fed ad libitum), and then used for reverse transcription and quantification of the absolute number of mRNA copies by qrtRT-PCR. Primers are depicted in Table I. Results obtained for $m C O Q$ mRNAs were normalized to those of $m H P R T$ as internal control. Data are means $\pm \operatorname{SEM}(\mathrm{n}=16)$. 

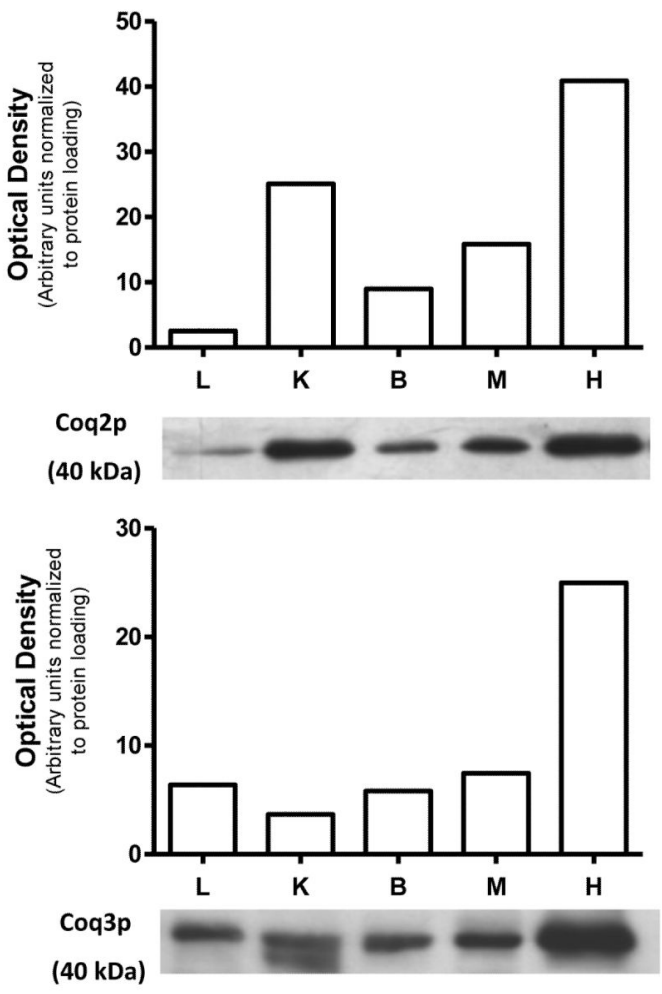

Figure 3.

Levels of Coq2p and Coq3p in mouse tissues. Samples of liver, kidney, brain, skeletal muscle and heart were obtained from control animals (fed ad libitum), and then processed for SDS-PAGE and immunodetection of the polypeptides of interest by Western blot. Staining was repeated in three different preparations. This figure depicts the results of a representative blot. 

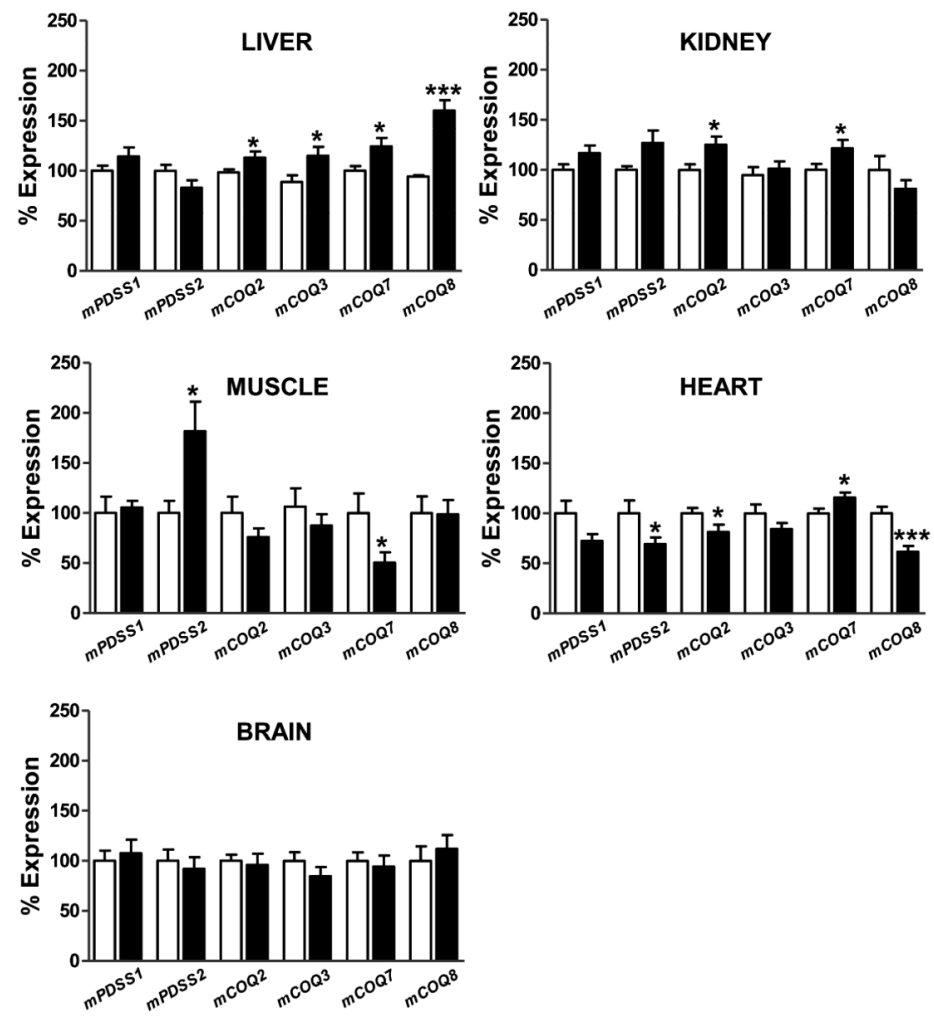

Figure 4.

The effect of short-term ( $1 \mathrm{mo}$ ) CR on steady-state abundance of $m C O Q$ mRNAs. RNA samples were extracted from liver, kidney, brain, skeletal muscle and heart obtained from animals fed ad libitum or under CR (1 mo). Samples were processed as described in Figure 2. Depicted results show the absolute number of copies of $m C O Q$ mRNAs present in tissues obtained from calorie-restricted animals, normalized to $m H P R T$ and then referred to the values obtained for the same tissue obtained from control animals (set to $100 \%$ in each case). Data are means \pm SEM ( $\mathrm{n}=16)$. Open bars, ad libitum; Closed bars : CR. 


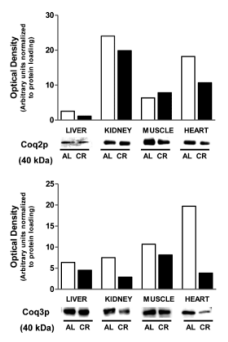

Figure 5.

The effect of short-term (1 mo) CR on steady-state abundance of Coq2p and Coq3p.

Samples of liver, kidney, brain, skeletal muscle and heart were obtained from control (fed $a d$ libitum) and from calorie-restricted animals, and then processed for SDS-PAGE and immunodetection of the polypeptides of interest by Western blot. Staining was repeated in three different preparations. This figure depicts the results of a representative blot. Open bars, ad libitum; Closed bars : CR. 
Table I

Primers for qrtRT-PCR used in the study

\begin{tabular}{|c|c|c|c|c|}
\hline PRIMERS & SENSE $\left(5^{\prime}-3^{\prime}\right)$ & ANTI-SENSE (5'-3') & $\begin{array}{l}\text { PRODUCT } \\
\text { SIZE (BP) }\end{array}$ & $\begin{array}{l}\text { GENBANK } \\
\text { ACCESSION NO. }\end{array}$ \\
\hline mHPRT & CAGTCAACGGGGGACATAAA & AGAGGTCCTTTTCACCAGCAA & 183 & NM_013556 \\
\hline mGAPDH & ATGGCCTTCCGTGTTCCTAC & GCCTGCTTCACCACCTTCTT & 104 & XM_194302 \\
\hline $\mathrm{m} 18 \mathrm{~S}$ & TGACTCAACACGGGAAACCT & AACCAGACAAATCGCTCCAC & 125 & X00686 \\
\hline mSPS1 & CATCAAAGGACACCAGCAATGT & GCACCACAATAATCGGTCTAAAGG & 208 & NM_019501 \\
\hline mDLP1 & ATGCTGACCTCCAGCCTTTT & GTCACACCTTTGCCAGCTTT & 196 & NM_027772 \\
\hline mCOQ2 & GCCCACCAGGACAAGAAAGAC & AGCCACAGCAGCGTAGTAGG & 171 & NM_027978 \\
\hline $\mathrm{mCOQ} 3$ & GTGAGCCACCTGGAAATGTT & CCCACGTATGAGTGCCTTTT & 163 & NM_172687 \\
\hline $\mathrm{mCOQ7}$ & TGATGGAAGAGGACCCTGAGAAG & GCCTGTATCGTGGTGTTCAAGC & 89 & NM_009940 \\
\hline $\mathrm{mCOQ8}$ & AGCAAGCCACACAAGCAGATG & CCAGACCTACAGCCAGACCTC & 106 & NM_023341 \\
\hline
\end{tabular}

